\title{
Nutritional Choices, New Health Approaches and Anti-speciesist Thinking
}

\author{
Biagio Tinghino \\ (Azienda Socio-Sanitaria Territoriale in Brianza; tinghino.biagio@gmail.com) \\ ORCID: 0000-0002-4043-8491
}

\begin{abstract}
Nutritional choices are affected by culture, tradition and above all by the narrative we adopt for human history. The article gives an overview of the (pseudo) scientific beliefs, psychological factors and ethical orientations that affect nutritional choices. Among the various food theories today, great importance is given, for example, to the so-called Paleolithic diet, which consists of proposing a dietary model based on blood groups, which are assumed to have developed throughout different periods of the natural evolution of Homo sapiens, which were characterized by peculiar alimentary regimes. Moreover, psychological determinant drivers affect food choices and could lead to pathological eating behaviors (e.g., anorexia, overeating, binge eating). Finally, the ethical aspects of nutrition are closely correlated to vegetarianism, which in turn embraces an anti-speciesist thinking and recognizes the need for humans not to inflict unnecessary suffering on animals. Vegetarianism, anti-speciesism and ecologism often represent different aspects of the same issue: a lifestyle that testifies the need for a change in traditional paradigms, in the interest of humankind and the future of life on our planet.
\end{abstract}

Keywords: Nutritional choices; vegetarianism; veganism; ecological nutrition; sustainable nutrition; food production and consumption; anti-speciesism; eating disorders; Paleolithic diet; food science.

\section{Historical Narration and Contemporary Theories on Food}

What we know, or what we think we know, what we narrate, or the narratives we decide to adopt, significantly influence the scientific research orientation and the development of theories on human nutrition ${ }^{1}$. The diet that uses animals as food or as food sources, for example, has been a pillar of human behavior, as far as we know, for thousands of years.

Recently, several theories in the nutritional field have been looking for a scientific foundation through a reconstruction of eating behaviors in the evolutionary history of Homo sapiens. The idea that humans have always eaten animals seems to constitute a "proof", on the basis of which dietary and sometimes therapeutic approaches find numerous followers. An example is the so-called "paleodiet", which, as one study indicates, is currently followed by 3 million Americans (D’Adamo \& Whitney 1996). It is a diet that 
only allows its followers to eat the foods typically eaten by their ancestors, who were hunter-gatherers, thus essentially preferring the use of meat, fruit and vegetables and excluding the consumption of processed foods, which would require cultivation or refining processes. These foods were difficult to obtain - according to the theory - when in this era humans had to quickly move from one area to another. Therefore cereals, cooked or prepared in any way, flour products, dairy products of all kinds were excluded.

This kind of diet seems to bring benefits when compared to the classic pathologies of our consumerist society, such as diabetes, hypercholesterolemia, metabolic syndrome (Schwartz \& Stapell 2013). Of course, there is no lack of criticism of this approach, or alternative explanations for the reasons why the exclusion of cereals and dairy products can be beneficial to some patients. An approach derived from the paleodiet is that of the so-called "blood groups", proposed by P. J. D’Adamo in the book Eat Right for Your Type (1996). This theory, which has many followers, is based on the hypothesis that each blood group corresponds to a phase of human evolution, as the antigens of the blood groups would have "stratified" or been added over thousands of years (Cordain et al. 2005; Schwartz \& Stapell 2013).

According to this theory, group $\mathrm{O}$ is considered the ancestral blood group, from the time when humans were hunter-gatherers. A paleodiet would be recommended for these people, as we said earlier. Subjects with group A should follow a vegetarian diet, because it is believed that this antigen was added to red blood cells when humans had already become sedentary, i.e., they were living on the products of agriculture (grains, legumes, fruit and vegetables). The type B diet would be related to people whose genetic characteristics correspond to the historical era of nomadism, therefore to individuals who ate dairy products and meat (Jingzhou et al. 2014). However, research has not found highlevel evidence to confirm these hypotheses and the majority of the scientific community remains skeptical (Tarantino et al. 2015).

However, this is a very interesting example of how a narrative concerning the past can influence food choices and can give them a scientific appearance. However, we note that evolutionary genetics has not yet clarified many lacunae of Darwinian theory ${ }^{2}$ and it still deals with processes that - with respect to macrophenomena such as speciation cannot be easily reproduced experimentally or observed directly. A decisive consideration

2 From the view of ethics, Darwin's and Mendel's discoveries have implications as follows: "when humans and non-human animals are part of a continuum, rather than qualitatively distinct forms of life, human meat-eaters confront a serious quandary. It becomes incumbent upon us to forge a contemporary justification for carnivorous behavior. Aristotle and Genesis will no longer do" (McWilliams 2011). Darwin's personal statement on vegetarianism can be documented with his letter to Karl Höchberg: as to justify human dietary choices, "the only evidence in my opinion which would be of any value, would be the statistics in regard of the amount of labor performed in countries where the population lived on a different diet. I have always been astonished at the fact that the most extraordinary workers I ever saw, viz., the laborers in the mines of Chili, live exclusively on vegetable food, which includes many seeds of the leguminous plants. On the other hand, the Gauchos are a very active people, and live almost entirely on flesh. Further, it appears to me to be good evidence that in tropical Africa an extraordinary craving exists, which increases to a necessity at times, to eat flesh, though I presume that the seeds of leguminous plants abound there, for the earth nut is extensively cultivated" (Darwin 1880,180). 
is also that no one can guarantee that hunter-gatherers were in good health - although this idea was already popular in Victorian Britain (see, e.g., Richardson 2019), or that a change in diet would have been harmful to them. We possess few elements to be able to define their physical condition, and in the light of the fact that life expectancy was about a few decades in the past, too little to see the effect of a diet on chronic degenerative diseases, which are characteristic of our age.

\section{Psychological Influences in Dietary Choices}

Nutrition is also fundamentally affected by psychic aspects, considered both as purely psychiatric traits and psychological or psycho-pathological characteristics. The pursuit of weight loss is now a constant in the choices of many people. Eating behaviors, as is known, can constitute nosographically assessed pathological entities, such as anorexia, binge eating disorder or anorexia nervosa. But there is also an important area of correlations between emotional eating, negative affectivity, lower levels of self-esteem and self-efficacy (Kemp et al. 2013; Leehr et al. 2015; Norwood et al. 2019; Shimpo et al. 2014). There are also studies in the literature that have explored the correlation between psychological factors and food choices, such as vegetarian or vegan diets. Being a vegetarian is associated with positive personal traits such as morality, empathy, an aptitude to sacrifice oneself for a greater good. But the goal of better health or the rejection of animals suffering could be strong motivations as well (Fox \& Ward 2008).

\section{Ethical and Ecological Orientation}

Alongside nutritional theories derived from an evolutionary narrative or favored by psychological traits, there is much discussion today about the compatibility between the various proposed models and environmental development and planetary economic sustainability. The expression "ecological nutrition" has many implications (Metz \& Hoffmann 2009; Schneider \& Hoffmann 2011). This concept encompasses several dimensions, including health, environment, but also economy and society. Food consumption is as just one link in a much longer chain, which includes agriculture, production and processing, sale, consumption and waste management. These aspects are taken into consideration within the ecological model with equal dignity and importance.

A fundamental element is the attention to environmental sustainability. The production of food, as we know, has strong repercussions on the environment. The production of carbon dioxide ( $\mathrm{CO} 2$ ), the consumption of resources, including water, land use, deforestation and the flora and fauna changing balance are factors that have great repercussions on society, health and economy (Rosengrant 2001; Steinfeld et al. 2006).

Vegetarian or vegan diets fall under an ecological nutritional model, but at the same time they often embrace an anti-speciesist philosophy, in the sense that they suggest that 
it is necessary to overcome the anthropocentric vision which involves humans inflicting indiscriminate oppression on natural elements and other species, even when this is not essential for their survival.

These choices are very diversified and range from abstaining from the consumption of meat or fish, or both, to abstaining from animal derivatives such as dairy products and eggs. Great attention is usually paid by vegetarians to the preference for "zero kilometer" food, grown with organic methods and not processed with pesticides. In general, seasonal foods are preferred.

While in the West the consumption of vegetables is being re-evaluated and vegetarian movement is growing, in countries that until now had based their diet on vegetables there is an increase in meat consumption. In India and China, demand for meat is rising as a result of industrialization and the adoption of Western lifestyles, of which meat consumption is considered a welfare indicator, even a status symbol. Overall, resource consumption for livestock farming is accelerating climate change phenomena, such as drought and arable soils desertification (Baroni et al. 2007). Even if the effects in the short term are inconspicuous, in the medium- and long-term vegetarianism reduces both the amount of water consumed for the production of fodder and deforestation, which finds its main reason in the urgency of having more pastures available, in order to breed cattle for slaughter. Consequently, plant-based diets have a favorable impact on energy consumption and CO2 production (Marlow et al. 2009).

Measuring the environmental impact of the various dietary regimes is complex and,

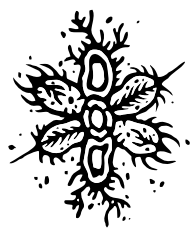
in any case, it must be related to the achievement of adequate nutritional standards. The measurement of the negative impacts on the environment caused by meat-based diets is plausible only when high meat consumption (above $50 \mathrm{~g}$ per day) occurs (American Institute for Cancer Research 2007). On the other hand, the sustainability of the Mediterranean Diet - which consists of a reduced animal-derived food consumption and is mostly based on the use of fruit, vegetables, legumes and grains - is well demonstrated (Dernini et al. 2017; Fresán \& Sabaté 2019; Serra-Majem \& Ortiz-Andrellucchi 2018).

\section{Effects on Human Health}

Both vegetarian and vegan diets, if well conducted, are suitable for every phase of life (Melina et al. 2016). The kinds of diet that are included under the definition of "vegetarianism", however, are different, so many that specific studies tend to differentiate between subspecies of diets, such as lacto-ovo-vegetarian, vegan, pescatarian, and so on. There is evidence that generally vegetarians have a lower BMI (Body Mass Index) than omnivores, a more favorable blood lipid profile (lower cholesterol and triglycerides), a reduced incidence of arterial hypertension, cardiovascular disease, metabolic diseases (e.g., type II diabetes) and arteriosclerosis. Numerous studies have shown a reduced incidence of cancer and insulin resistance (Clarys 2014; Key et al. 2009; Rohrmann et al. 
2013; Pilis et al. 2014; World Health Organization 2003).

However, most of these studies are conducted on the Western population which has a high level of economic well-being and a high cultural standard. A vegetarian diet, especially a vegan one, conducted without adequate nutritional knowledge, that guides the choice and combination of foods, can expose people - more than the omnivorous diet - to the risk of anemia due to iron deficiency, vitamin B12 deficiency, protein deficiency and hyperhomocysteinemia.

In conclusion, the need to assess the impact of an anti-speciesist cultural approach on eating behaviors has become increasingly urgent. The resulting food choices can have an important impact on our quality of life, not so much and not only as individuals, but above all in global terms and with reference to the environment. Anti-speciesism, vegetarianism, ecological orientation, might soon become topics discussed out of the narrow circle of enthusiasts and supporters, and together with other key points they prove to be critical junctures, on the base of which we will be called to make choices in the interest of humankind and the future of life on our planet.

\section{References}

Baroni L., Cenci L., Tettamanti M., \& Berati M. 2007. "Evaluating the Environmental Impact of Various Dietary Patterns Combined with Different Food Production Systems," European Journal of Clinical Nutrition 61(2):279-286.

Clarys P., Deliens T., Huybrechts I., Deriemaeker P., Vanaelst B., De Keyzer W., et al. 2014.

"Comparison of Nutritional Quality of the Vegan, Vegetarian, Semi-vegetarian, Pesco-vegetarian and Omnivorous Diet," Nutrients 6(3):1318-1332. DOI: 10.3390/ nu6031318.

Cordain L., Eaton S. B., Sebastian A., Mann N., Lindeberg S., Watkins W. A., et al. 2005. "Origins and Evolution of the Western Diet: Health Implications for the $21^{\text {st }}$ Century," American Journal of Clinical Nutrition 81:341-354.

D’Adamo P. \& Whitney C. 1996. Eat Right 4 Your Type: The Individualized Diet Solution to Staying Healthy, Living Longer \& Achieving Your Ideal Weight. New York: Putnam.

Darwin Ch. 1880. "Darwin's Reply to a Vegetarian," Herald of Health and Journal

of Physical Culture 31:180. URL: http://darwin-online.org.uk/content/ frameset?pageseq=1\&itemID=F1984\&viewtype=text.

Dernini S., Berry E. M., Serra-Majem L., La Vecchia C., Capone R., Medina F. X., et al. 2017. "Med Diet 4.0: the Mediterranean Diet with Four Sustainable Benefits," Public Health Nutrition 20(7):1322-1330. DOI: 10.1017/S1368980016003177.

Fox N. \& Ward K. J. 2008. "You Are What You Eat? Vegetarianism, Health and Identity," Social Science \& Medicine 66:2585-2595. DOI: 10.1016/j.socscimed.2008.02.011. 
Fresán U. \& Sabaté J. 2019. "Vegetarian Diets: Planetary Health and Its Alignment with Human Health," Advances in Nutrition 10(4):S380-S388. D0I: 10.1093/advances/ nmz019.

Jingzhou W., García-Bailo B., Nielsen D. E., \& El-Sohemy A. 2014. “ABO Genotype, 'Blood-Type' Diet and Cardiometabolic Risk Factors PLoS One," PLoS ONE 9(1). DOI: 10.1371/journal.pone.0084749.

Kemp E., Bui M., \& Grier S. 2013. "When Food Is More Than Nutrition: Understanding Emotional Eating and Overconsumption," Journal of Consumer Behaviour 12:204213. DOI: $10.1002 / c b .1413$.

Key T. J., Appleby P. N., Spencer E. A., Travis R. C., Roddam A. W., \& Allen N. E. 2009. "Cancer Incidence in Vegetarians: Results from the European Prospective Investigation into Cancer and Nutrition (EPIC-Oxford)," The American Journal of Clinical Nutrition 89(5):1620S-1626S. DOI: 10.3945/ajcn.2009.26736M.

Leehr E. J., Krohmer K., Schag K., Dresler T., Zipfel S., \& Giel K. E. 2015. “Emotion Regulation Model in Binge Eating Disorder and Obesity - a Systematic Review," Neuroscience and Biobehavioural Reviews 49:125-134. D0I: 10.1016/j. neubiorev.2014.12.008.

McWilliams J. 2011. “Foodies vs. Darwin: How Meat-Eaters Ignore Science,” The Atlantic (Section Health), May 19. URL: https://www.theatlantic.com/health/ archive/2011/05/foodies-vs-darwin-how-meat-eaters-ignore-science/239127/.

Marlow H. J., Hayes W. K., Soret S., Carter R. L., Schwab E. R., \& Sabaté J. 2009. “Diet and the Environment: Does What You Eat Matter?" The American Journal of Clinical Nutrition 89(5):1699S-1703S. DOI: 10.3945/ajcn.2009.26736Z.

Melina V., Craig W., \& Levin S. 2016. "Position of the Academy of Nutrition and Dietetics: Vegetarian Diets," Journal of the Academy of Nutrition and Dietetics 116(12):19701980. DOI: 10.1016/j.jand.2016.09.025.

Metz M. \& Hoffmann I. 2009. "Effects of Vegetarian Nutrition - A Nutrition Ecological Perspective," Nutrients 2(5):496-504. DOI: 10.3390/nu2050496.

Norwood R., Cruwys T., Chachay V. S., \& Sheffield J. 2019. “The Psychological Characteristics of People Consuming Vegetarian, Vegan, Paleo, Gluten Free and Weight Loss Dietary Patterns," Obesity Science \& Practice 5(2):148-158. DOI: $10.1002 /$ osp 4.325.

Pilis W., Stec K., Zych M., \& Pilis A. 2014. "Health Benefits and Risk Associated with Adopting a Vegetarian Diet," Roczniki Państwowego Zakładu Higieny 65(1):9-14.

Richardson E. 2019. "Man Is Not a Meat-Eating Animal: Vegetarians and Evolution in Late-Victorian Britain," Victorian Review 45(1):117-134. DOI: https://doi. org/10.1353/vcr.2019.0034. 
Rohrmann S., Overvad K., Bueno-de-Mesquita H. B., Jakobsen M. U., Egeberg

R., Tjønneland A., et al. 2013. "Meat Consumption and Mortality - Results from the European Prospective Investigation into Cancer and Nutrition," BMC Medicine 11. DOI: 10.1186/1741-7015-11-63.

Rosegrant M., Paisne M. S., Meije S., \& Witcover J. 2001. 2020 Global Food Outlook.

Trends, Alternatives and Choices. International Food Policy Research Institute. URL: https://www.ifpri.org/ .

Schneider K. \& Hoffmann I. 2011. "Nutrition Ecology-a Concept for Systemic Nutrition Research and Integrative Problem Solving," Ecology of Food and Nutrition 50(1). DOI: $10.1080 / 03670244.2010 .524101$.

Schwartz D. B. \& Stapell H. M. 2013. "Modern Cavemen? Stereotypes and Reality of the Ancestral Health Movement," Journal of Evolution and Health 1(1):1-19. DOI: 10.15310/2334-3591.1000.

Serra-Majem L. \& Ortiz-Andrellucchi A. 2018. "The Mediterranean Diet as an Example of Food and Nutrition Sustainability: A Multidisciplinary Approach," Nutricion Hospitalaria 12(35):96-101. DOI: 10.20960/nh.2133.

Shimpo M., Fukkoshi Y., \& Akamatsu R. 2014. “Correlations between Self-efficacy in Resisting Six Temptations and Dietary Energy and Macronutrient Intake at Each Meal," Eating Behaviours 15:563-566. DOI: 10.1016/j.eatbeh.2014.08.012

Steinfeld H., Gerber P., Wassenaar T., Castel V., Rosales M., \& de Haan C. 2006. Livestock's Long Shadow. Environmental Issues and Options. United Nations Food and Agriculture Organization. URL: http://www.fao.org/home/en/ .

Tarantino G., Citro V., \& Finelli C. 2015. "Hype or Reality: Should Patients with Metabolic Syndrome-related NAFLD Be on the Hunter-gatherer (Paleo) Diet to Decrease Morbidity?," Journal of Gastrointestinal and Live Diseases 24(3):359-368. DOI: 10.15403/jgld.2014.1121.243.gta.

World Cancer Research Fund/American Institute for Cancer Research. 2007. Food, Nutrition, Physical Activity, and the Prevention of Cancer: A Global Perspective. American Institute for Cancer Research. URL: https://www.aicr.org/ .

World Health Organization/Food and Agriculture Organization of the United Nations. 2003. Diet, Nutrition, and the Prevention of Chronic Diseases: Report of a Joint WHO/FAO Expert Consultation (Technical Report Series no. 916). World Health Organization. URL: https://www.who.int/. 